Article

\title{
Nutrient Control to Prevent the Occurrence of Cyanobacterial Blooms in a Eutrophic Lake in Southern Sweden, Used for Drinking Water Supply
}

\author{
Jing Li ${ }^{1, *(\mathbb{D})}$, Lars-Anders Hansson ${ }^{2}$ and Kenneth M. Persson ${ }^{1,3}$ \\ 1 Department of Building and Environmental Technology/Water Resources Engineering, Lund University, \\ PO Box 118, SE-221 00 Lund, Sweden; kenneth_m.persson@tvrl.lth.se or Kenneth.m.persson@swrab.se \\ 2 Department of Biology/Aquatic ecology, Lund University, Sölvegatan 37, SE-223 62 Lund, Sweden; \\ lars-anders.hansson@biol.lu.se \\ 3 Sweden Water Research AB, Ideon Science Park, SE-223 70 Lund, Sweden \\ * Correspondence: jing.li@tvrl.lth.se, Tel.: +46-46-222-94-70
}

Received: 24 April 2018; Accepted: 27 June 2018; Published: 11 July 2018

\begin{abstract}
Control of nutrients, mainly nitrogen $(\mathrm{N})$ and phosphorus $(\mathrm{P})$, plays a significant role in preventing cyanobacterial blooms (harmful algal blooms (HABs)). This study aims at evaluating changes in the risk of the occurrence of cyanobacterial blooms and advancing the understanding of how nitrogen and phosphorus affect the growth of cyanobacteria in a eutrophic lake, Lake Vombsjön, in southern Sweden. Our results show that TP (total phosphorus) has stronger positive correlation with cyanobacteria biomass than DIP (dissolved inorganic phosphorus); DIN (dissolved inorganic nitrogen) has a stronger negative correlation with cyanobacteria biomass than TN (total nitrogen); and DIN:TP has a stronger negative correlation with cyanobacteria biomass than TN:TP. The highest amount of cyanobacteria biomass, above WHO (World Health Organization) Alert Level $2\left(10 \mathrm{~mm}^{3} / \mathrm{L}\right.$ ) for drinking water correspond to the DIN/TP ratio below 10. To diminish the growth of cyanobacteria in Lake Vombsjön, TP and DIN control should be in focus, preferably a TP below $20 \mu \mathrm{g} / \mathrm{L}$, and the DIN:TP ratio should be maintained at a level of at least above 10, but preferably above 50 , thereby reducing the likelihood for a nitrogen limiting situation which may favor cyanobacteria dominating blooms.
\end{abstract}

Keywords: phosphorus; nitrogen; TN:TP ratio; DIN:TP ratio; Cyanobacteria; Lake Vombsjön

\section{Introduction}

Harmful algal blooms (HABs), specifically those caused by cyanobacteria, have become one of the most critical concerns for drinking water supply, as well as for maintaining the ecological and economic sustainability of freshwater ecosystems worldwide [1,2]. Eutrophication is the major process stimulating the growth of algal and cyanobacterial biomass, the key factors here being the maintaining of a high availability of important nutrients, such as phosphorus $(\mathrm{P})$ and nitrogen $(\mathrm{N})$, and also a low N/P ratio [3,4]. Cyanobacterial blooms are predicted to become even more common due to climate warming [2,5]. Recent studies have also demonstrated that synergies between climate warming and increasing levels of humic substances in runoff are able to trigger an increase in cyanobacteria biomass [6], as well as a reduction in the biodiversity of phytoplankton [7,8]. Accordingly, both global and local scale adaptive management tools are important to manage future challenges related to water security and adequate functioning of freshwater ecosystems [7].

Regarding drinking water supply, major reasons for the strong impact of cyanobacterial blooms are that large algal blooms tend to clog the treatment process. They also cause unpleasant smells, 
may produce toxins [7-9], and are difficult to remove [10]. There is even a cyanotoxin risk in the sludge managed at drinking water treatment plants [11]. Nearly all eutrophic freshwater bodies contain toxic cyanobacteria though the size of cyanobacterial populations may also be dependent upon such environmental conditions, temperature, mixing regimes, transparency, and the availability of iron or carbon [12-15].

Hence, to meet future challenges with respect to ecosystem services, such as the provision of clean drinking water, it is crucial to reduce the input of nutrients to aquatic ecosystems [16-18]. Phosphorus is commonly considered to be the limiting nutrient in freshwater ecosystems [19], and high concentrations of $\mathrm{P}$ often co-occur with severe cyanobacterial blooms in many regions of the world, such as in large lakes in North America and in China [20,21]. To reduce the probability that the biomass of HABs reach concentrations above WHO Alert Level $1\left(0.2 \mathrm{~mm}^{3} / \mathrm{L}\right)$ for drinking waters [1] in Swedish lakes, it has been recommended to reduce TP (total phosphorus) below $20 \mu \mathrm{g} / \mathrm{L}$ in this particular region and climate [22].

Although phosphorus is generally the main limiting nutrient for cyanobacterial growth in freshwaters, nitrogen may sometimes be co-limiting, since it is a quantitatively important bio-element [23]. However, contrary to most other planktonic algae, some cyanobacteria are able to fix atmospheric nitrogen in a nitrogen-limiting situation, which can lead to a lack of nitrates or of ammonia, and in turn to a dominance of $\mathrm{N}_{2}$-fixing cyanobacteria such as Anabaena spp. and Aphanizomenon spp. [24]. For instance, the drop of dissolved inorganic nitrogen (DIN) correlated with an increase of $\mathrm{N}_{2}$ fixation rates and Aphanizomenon abundance in the eutrophic Lake Mendota, Wisconsin, USA [25]. Another example is that under nitrogen-limiting conditions the abundance of various common toxic cyanobacteria, such as Microcystis aeruginosa, which are not capable of fixing $\mathrm{N}_{2}$, declines, whereas their biomass increases again as nitrogen becomes more readily available [26]. Because of differences in the $\mathrm{N}_{2}$ fixation capabilities involved, many studies have examined interactions between cyanobacterial blooms and the nutrients available to them. For example, in Lake Taihu, China, the availability of $\mathrm{P}$ has been found to control the pre-bloom conditions of Microcystis spp. during the spring months, whereas the availability of $\mathrm{N}$ controls the blooms of this species during the summer months. The thresholds for the limitations of TN and TP were estimated to below $800 \mu \mathrm{g} / \mathrm{L}$ and below $50 \mu \mathrm{g} / \mathrm{L}$, respectively [16].

In addition to the absolute concentrations of the nutrients, the ratio of nitrogen to phosphorus (the $\mathrm{N}: \mathrm{P}$ ratio) has been considered to be one of the main parameters in determining cyanobacterial growth $[4,5,27]$. Keeping the absolute concentrations of $\mathrm{N}$ and $\mathrm{P}$ at low levels and combined with this, maintaining a high TN:TP ratio above 30, reduces the risk of cyanobacterial blooms [28]. A high concentration of $\mathrm{P}$ and a low N:P ratio tend to favour the development of cyanobacterial blooms [29], since for some species, nitrogen deficits may be compensated by nitrogen fixation from the atmosphere. However, a low N:P ratio does not always lead to a nitrogen limiting situations and nitrogen fixation conditions, since it is also affected by the phytoplankton biomass and by the nitrogen concentration [4]. Hence, a low N:P ratio alone does not suffice for appreciably limiting the development of cyanobacterial blooms. In this study, we thus compared the influence of DIN, DIP (dissolved inorganic phosphorus), TP, TN, TN:TP, and DIN:TP on cyanobacteria biomass separately and tested if DIN:TP was a better indicator of cyanobacteria peaks.

From both a research and a management perspective, it is highly important to identify and control environmental processes that have the potential of driving and sustaining cyanobacterial blooms [30]. Beside nutrient reduction, there are many factors influencing ecosystem function, such as shifting baselines where changes in forcing factors other than nutrients, such as climate and food web structure. Understanding how ecosystems respond to multiple shifting baselines is essential in order to set reliable targets for restoration efforts [31]. For a successful monitoring of ecosystem transitions, a priori specific knowledge of the underlying processes/mechanisms driving ecosystem transitions is required [32]. The more eutrophic a lake is, the more sensitive cyanobacteria will be to the interactions between nutrients and temperature, but ultimately the nutrient level is the more important predictor for cyanobacterial biomass development [33]. To reduce cyanobacteria growth, 
we need system-specific analytic and management approaches of different kinds, which define the combined monitoring of nutrient concentrations, cyanobacteria and cyanotoxin concentrations [22].

To obtain a better understanding on how nutrient concentrations and nutrient ratios affect the frequency and intensity of cyanobacterial blooms and the ecosystem services provided by lakes, long-term data for Lake Vombsjön, in southern Sweden, which serves as a raw water resource for more than 500,000 inhabitants, were collected and evaluated. We examined seasonal, as well as long-term trends in nutrient levels, in N:P and DIN:TP ratios, in phytoplankton species compositions and in their interactions. The rationale for the study was to use a model lake, Lake Vombsjön, to obtain a detailed understanding of the formation of harmful cyanobacterial blooms, which could serve as a basis for a general understanding of efficient management of eutrophic lakes.

We employed system analysis and statistical analysis to identify the critical nutrient drivers of harmful algal blooms and seasonal patterns of phytoplankton dominance. By using a long-term time series from a eutrophic lake in southern Sweden as model system, we specifically tested the hypothesis that DIN/TP might be a better precursor, and even an early warning signal [32] for cyanobacterial blooms.

\section{Materials and Methods}

Lake Vombsjön is part of Kävlingeån River's catchment area (See Figure S1). It is situated 20 km east of the city of Lund. The main type of land use within the catchment area are agriculture $(72 \%)$ and forestry $(23 \%)$, whereas urban living areas $(3 \%)$ and lakes $(2 \%)$ cover only a minor portion of the area. The lake has a surface area of approximately $12 \mathrm{~km}^{2}$ and the average and a maximum depths of 9.4 and $16.0 \mathrm{~m}$, respectively [34]. The lake has a turnover time of 1.04 years. The main inflow to the lake is that from the Björkaån River $\left(76 \%\right.$ ). Some $20 \%$ of the water flow (of $31 \mathrm{Mm}^{3} /$ year) from Lake Vombsjön is used for drinking water.

Due to Lake Vombsjön being located in what is both an agricultural and a highly populated region, the water quality of the lake suffers considerably from the leaching of nutrients and pesticides from the wastewater and agriculture. More than $85 \%$ of the external phosphorus and nitrogen load is from agricultural activities [35]. The accumulation of large amounts of nutrients in the lake sediments has also become a challenge for nutrient management of the lake.

Data on nutrients in the outlet from Lake Vombsjön was collected from 1990 to 2016 within the framework of the regional and national environmental water recipient monitoring program (Vattenanknuten recipientkontrollprogram [36]), led by the Kävlingeåns Water Protection Agency [37]. Data was analyzed by ALcontrol AB, methods for TP $\mu \mathrm{g} / \mathrm{L}$ : SS-EN ISO 156812:2005, TN $\mu \mathrm{g} / \mathrm{L}$ : SS-EN

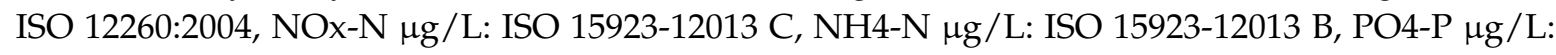
SS-EN ISO 6878:2005 [38]. Dissolved inorganic nitrogen (DIN) is the sum of NOx-N and NH4-N.

Phytoplankton data from 1989 to 2010 was provided by the county board of Scania and was analyzed using the method of Utermöhl for quantitative assessment of phytoplankton [39]. Data for 2016 was provided by Sydvatten AB, one of the largest water suppliers in southern Sweden. Samples were taken of the incoming water to the drinking water treatment plant in the area (the Vomb water treatment plant) [40].

To assess the relationship between nutrients and phytoplankton data, we used the non-parametric Spearman's rank correlation coefficient. The Spearman's correlation between two variables will be high when the observations have a similar rank (or identical for a correlation of 1 ) and low when the observations have a dissimilar (or completely opposite for a correlation of -1 ) rank. $p$-Value is the significant level which shows the likelihood that the two variables are uncorrelated [41]. Boxplots were used to visualize the seasonal pattern of cyanobacteria and the variation of its percentage in the phytoplankton community. 


\section{Results and Discussion}

\subsection{Nutrient Condition at Lake Vombsjön}

Temporal nutrient trends in the main inflow to Lake Vombsjön, the Björkaån River, have shown an increasing tendency during recent decades (See Figure S2a). In contrast, there has been a decreasing trend in both TN and TP concentrations at the main outlet from Lake Vombsjön, although the levels have remained high with average concentrations of around $1000 \mu \mathrm{g} / \mathrm{L}$ and $55 \mu \mathrm{g} / \mathrm{L}$, respectively (See Figure S2b). Thus, very large amounts of nutrients have remained in the lake, as can be seen as in See Figure S2c, which also demonstrates a considerable potential for nutrients to accumulate in the lake. For the period reported in this study, phosphorus deposition in the lake sediments was below 1 ton per year. This translates to an internal $\mathrm{P}$ load of which approximately $38 \%$ (corresponding to 226 tons) involves three $\mathrm{P}$ fractions, which are not stable but instead can readily be released into the water [42]. The TN load has reached about 914 tons per year, $96 \%$ of which is from diffuse sources, specifically from agriculture, forests, and pasture lands [43]. The large amounts of nutrients provide a considerable opportunity for algae to grow. In a Swedish national research project, entitled WATERS, aimed at obtaining a dataset for the ecological assessment of Swedish water bodies, it was found that levels of $\mathrm{TP}>20 \mu \mathrm{g} / \mathrm{L}$ or of $\mathrm{TN}>500 \mu \mathrm{g} / \mathrm{L}$ were indicative of a heightened risk of health-related problems connected with cyanobacteria [44]. In line with this, it may be concluded that Lake Vombsjön is not in a healthy state since TP levels are about two times higher, and TN levels about four times higher than the recommended thresholds.

\subsection{Seasonal Pattern of Cyanobacteria}

Heavy algal blooms have been observed in Lake Vombsjön almost every summer since the 1970s. There is a clear seasonal pattern in the cyanobacterial development, which often starts with an initial bloom in spring, followed by an increase during July and August, which generally peaks in September and then eventually declines (Figure 1a). In July, the median values of cyanobacteria biomass generally exceed the WHO alert level 1, $0.2 \mathrm{~mm}^{3} / \mathrm{L}$ for drinking waters (blue line in Figure 1a) [1]. More than $80 \%$ of the samples obtained during the past 26 years have been above alert level 1 and $13 \%$ have been above the WHO Alert level 2, $\left(10 \mathrm{~mm}^{3} / \mathrm{L}\right)$ for drinking waters. The Finnish National Supervisory Authority for Welfare and Health has chosen $0.1 \mathrm{~mm}^{3} / \mathrm{L}$ as national alert level 1 for operators of drinking water treatment plants to increase raw water monitoring and $1 \mathrm{~mm}^{3} / \mathrm{L}$ for actions to be initiated, such as risk assessment and information to authorities [45]. Since in general 50-75\% of algal blooms are toxic [46], this suggests that raw water taken from the lake for drinking water purposes might frequently be toxic during bloom seasons. We also found that the later in the season a bloom occurs, the more likely it is dominated by cyanobacteria (Figure 1b). During the period of September to November the percentage of cyanobacteria present in the phytoplankton community was often above $80 \%$ (Figure 1b), suggesting that monitoring of algal blooms in late autumn is crucial.

\subsection{Nutrients Influence on Cyanobacteria}

As Lake Vombsjön is rich in nutrients, it provides suitable condition for cyanobacteria to grow. However, it remains to be determined whether TP, TN, DIN, and DIP have different influences on cyanobacteria growth and if low DIN:TP is more accurate than low TN:TP as an indicator for cyanobacteria peaks in Lake Vombsjön.

The long-term time series of samples from Lake Vombsjön demonstrates a clear seasonal pattern in the TN:TP ratio, where TN:TP in the outlet decreased more than in the inlet from June and onwards. Before the end of June, the TN:TP ratio in the outlet was in general above 50 and during the rest of the year the ratios were below 20 (Figure 2). The former might indicate the lake water at the first half of the year under $\mathrm{P}$ limiting conditions, whereas the latter might indicate $\mathrm{N}$ limiting conditions. A similar pattern was observed in the Great Lakes of the USA [47]. It might further indicate that the dominance of cyanobacteria during summer and autumn (Figure 1b) was caused by a transition from 
phosphorus to nitrogen limiting conditions. One of the likely reasons behind the seasonal pattern in TN:TP ratios, which declines during the summer and autumn (Figure 2), might be the increase of phosphorus concentrations at the outflow of the lake (See Figure S3), possibly caused by phosphorus leakage from the sediment (resulting in internal phosphorus loading). At the same time, $\mathrm{N}$ depletion in the autumn also contributed to the decrease in TN:TP ratios (See Figure S4).

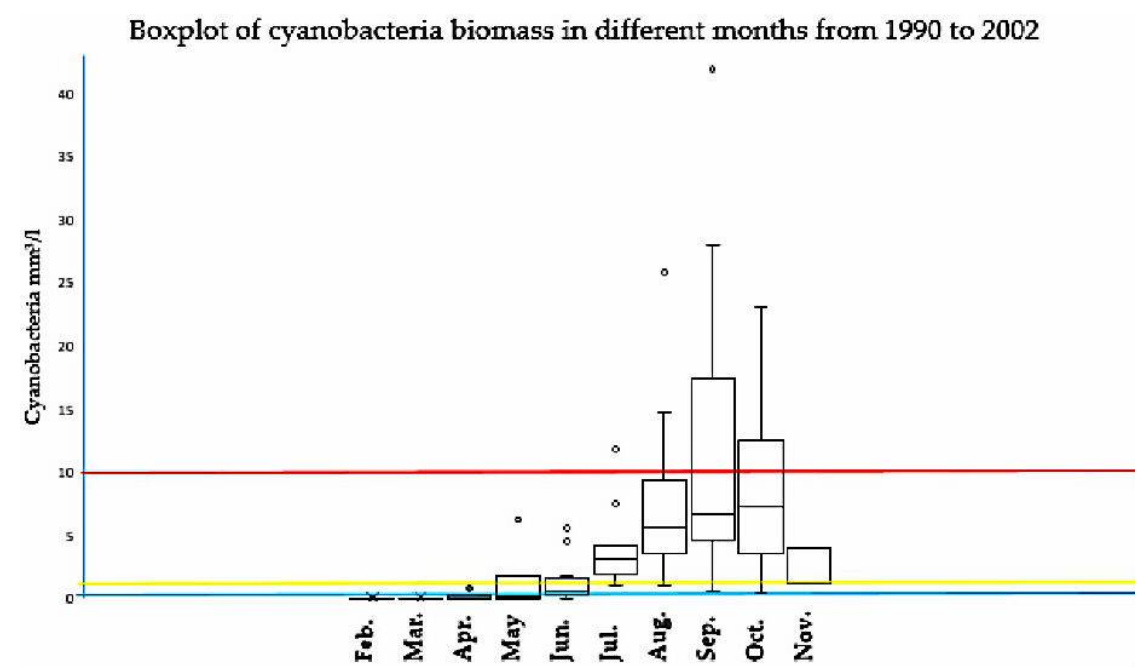

(a)

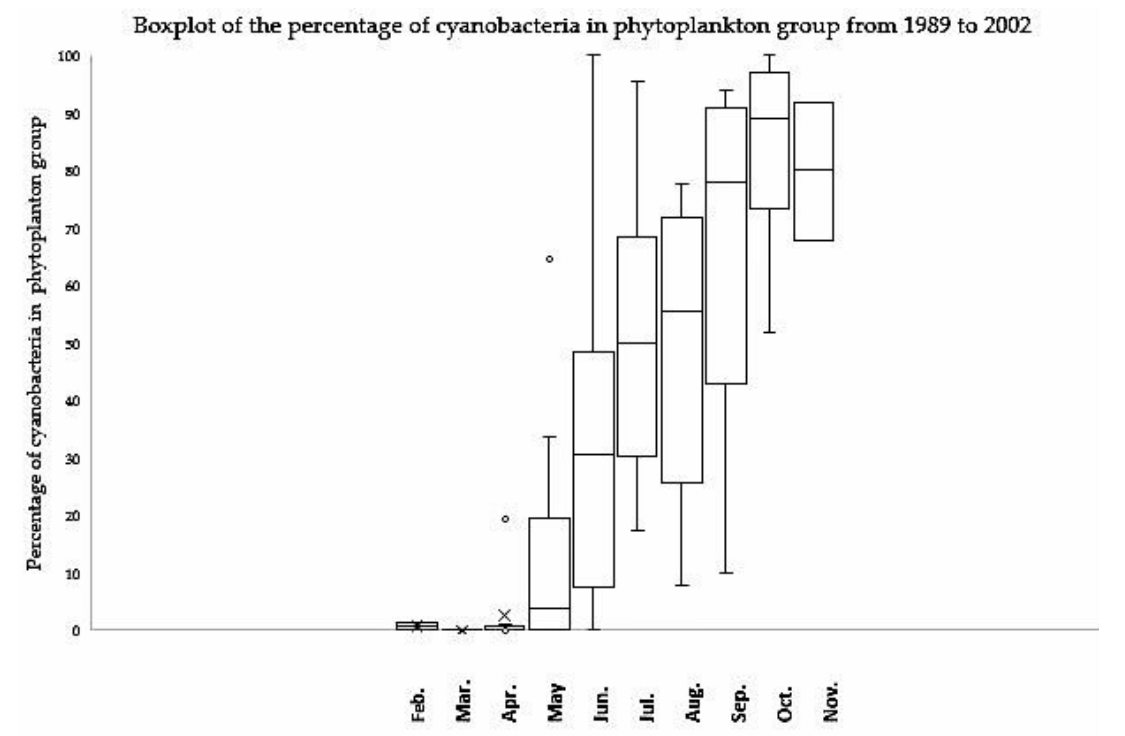

(b)

Figure 1. (a) Seasonal patterns of cyanobacteria biomass $\left(\mathrm{mm}^{3} / \mathrm{L}\right)$ in Lake Vombsjön during 1990 to 2002 (the blue line: $0.2 \mathrm{~mm}^{3} / \mathrm{L}$ is WHO (World Health Organization alert level 1 for drinking water waters; yellow line $1 \mathrm{~mm}^{3} / \mathrm{L}$ is Finnish drinking water for actions taken such as risk assessment and inform authorities; Red line is $10 \mathrm{~mm}^{3} / \mathrm{L}$ is WHO alert level 2 for drinking waters); (b) Seasonal patterns of cyanobacteria relative abundance found in Lake Vombsjön 1989-2002. 


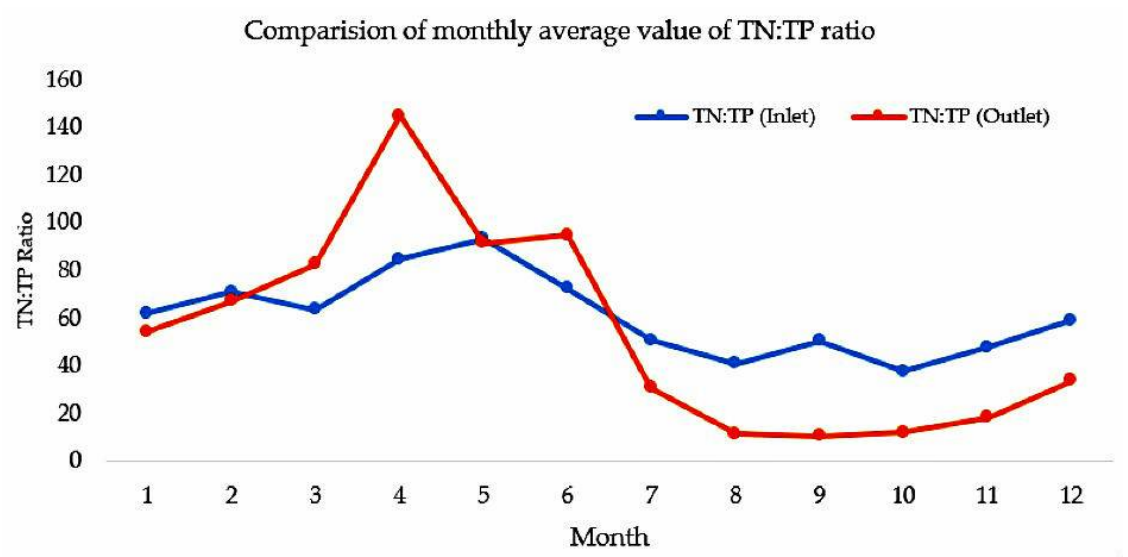

Figure 2. Seasonal patterns of TN:TP (total nitrogen:total phosphorus) ratios at both inlet and the outlet of Lake Vombsjön.

The correlation between cyanobacteria biomass and TP, TN, DIP, and DIN in Lake Vombsjön shows that TP has a stronger positive correlation with cyanobacteria biomass than DIP, and that DIN has a stronger negative correlation with cyanobacteria biomass than TN. Therefore, DIN:TP predicts cyanobacteria biomass development better than TN:TP (Table 1 and Figures 3-5). Low DIN corresponded to high cyanobacteria biomass, suggesting that certain cyanobacteria thrive under nitrogen limiting conditions. This might also reflect the autumn (September) situation characterized by more nitrogen limiting conditions. Morris and Lewis (1988) supported that TP is better than dissolved phosphorus for $\mathrm{P}$ availability measurements as it includes internal stores of $\mathrm{P}$, while dissolved nitrogen is better than TN for availability measurements, as TN includes various non-available components, whereas luxury uptake of $\mathrm{N}$ is limited [48]. This may explain why cyanobacteria dominate when there are large amounts of dissolved phosphorus released from the sediment that coincide with very limited dissolved nitrogen availability in the lake. As discussed by Dolman and Wiedner, DIN/TP might be a better indicator of nutrient limitation than TN:TP and the influence of nitrogen on freshwater phytoplankton biomass might need more attention [49]. Previous empirical studies observed values of DIN/TP ratios in the range of 0.5-4 (mass) to discriminate between the outcomes of nutrient addition experiments and to do so better than the TN:TP [48,50]. Furthermore, it was shown that nitrogen availability might matter in the genetic regulation of toxin production as discussed by Steffen and others, wherein their statistical examination of Canadian lakes showed a correlation between microcystin concentration and low N:P ratios [48]. Hence this suggests that besides studying the phosphorus dynamics, it is crucial to also monitor DIN and understand how the nitrogen cycle is influencing cyanobacteria. In Lake Vombsjön, the highest amount of cyanobacteria biomass, $>10 \mathrm{~mm}^{3}$, correspond to DIN/TP values of less than 10, whereas the lowest biomass are recorded when DIN/TP is above 50 (Figure 6). Hence, it may be concluded that trends in DIN/TP ratios may function as "early warning signals" for developing cyanobacterial blooms, suggesting that managers should be more aware of, and monitor, DIN/TP values, especially in late summer and autumn.

Table 1. Correlations between concentration of cyanobacteria and TN, DIN (dissolved inorganic nitrogen), TP, DP (dissolved phosphorus), TN:TP, and DIN:TP in Lake Vombsjön, and resulting $p$-values (Spearman's rs).

\begin{tabular}{ccccccc}
\hline Item & TN & DIN & TP & DP & TN:TP & DIN:TP \\
\hline $\begin{array}{c}\text { Correlation Coefficient } \\
p \text {-Values }\end{array}$ & -0.56 & -0.65 & 0.62 & 0.31 & -0.63 & -0.66 \\
& $<0.001$ & $<0.001$ & $<0.001$ & $<0.001$ & $<0.001$ & $<0.001$ \\
\hline
\end{tabular}


Scatter plot of log value of cyanobacteria concentration VS

$\log$ value of DIP and TP

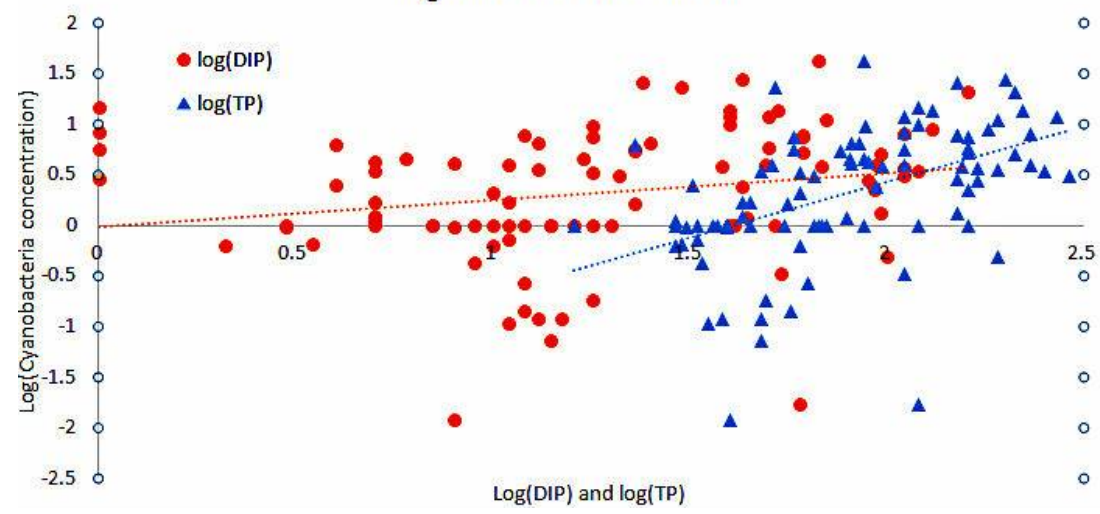

Figure 3. Comparison of the relation of dissolved inorganic phosphorus (DIP) with cyanobacteria biomass (dot red) and TP with cyanobacteria biomass (triangle blue).

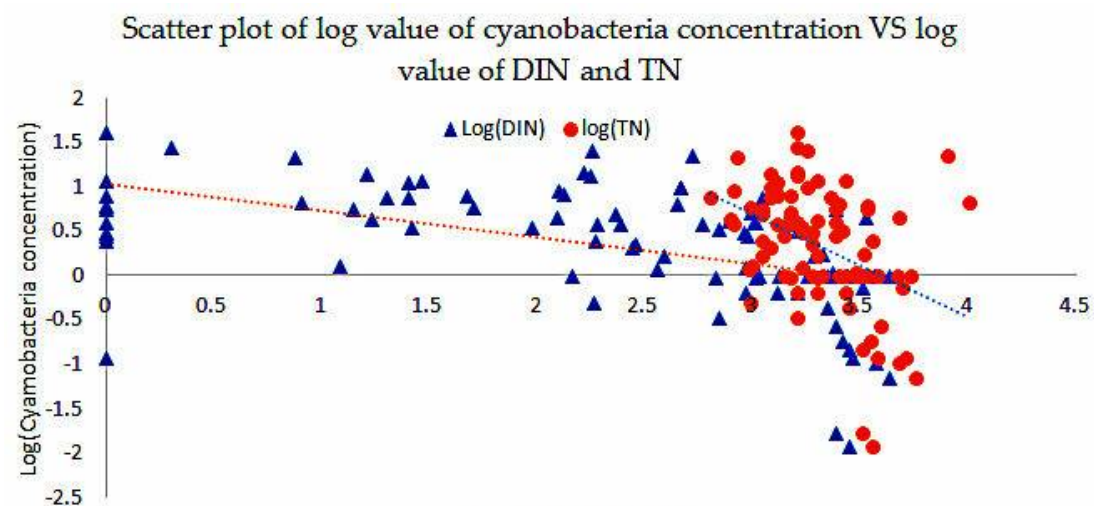

$\log (\mathrm{DIN})$ and $\log (\mathrm{TN})$

Figure 4. Comparison of the relation of dissolved inorganic nitrogen (DIN) with cyanobacteria biomass (triangle blue) and TN with cyanobacteria biomass (dot red).

\section{Scatter plot of log value of cyanobacteria biomass VSlog value of \\ DIN:TP and TN:TP}

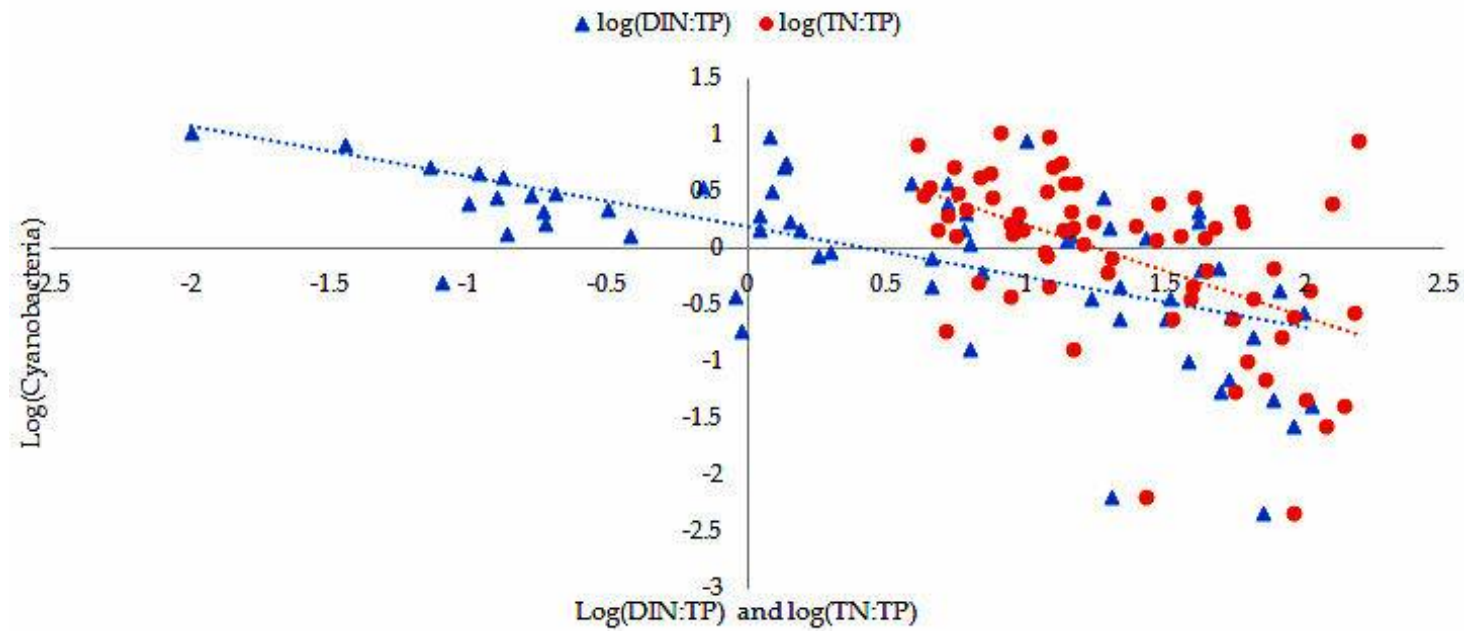

Figure 5. Comparison of the relation of DIN:TP with cyanobacteria biomass (triangle blue) and TN:TP with cyanobacteria biomass (dot red). 
DIN:TP VS cyanobacteria

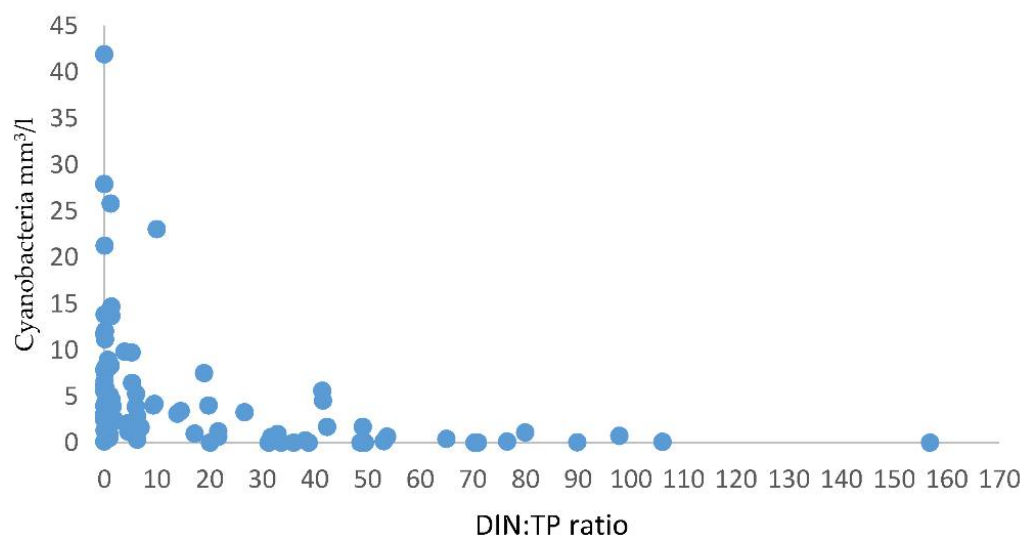

Figure 6. Plot of DIN:TP and cyanobacteria biomass; it is likely to conclude that low DIN:TP $(<10)$ corresponds cyanobacteria peaks.

\section{Conclusions}

The long-term monitoring of Lake Vombsjön provides further understanding of the mechanisms behind cyanobacteria growth and blooms. Our study also highlights the importance of monitoring cyanobacterial blooms during the period from July to November, with a particular focus on September. Our findings suggest that reducing the amount of total phosphorus is a key for reducing the risk of cyanobacterial blooms, but that the nitrogen availability, such as DIN, plays a very important role for the phytoplankton dynamics and that cyanobacteria often dominate under $\mathrm{N}$ limiting conditions. DIN should be monitored more carefully than TN as it is a better indicator of nitrogen availability than TN. It is especially important to control TP under N depletion, as our data analysis also brought to light the importance of DIN/TP relative to that of TN:TP for extreme cyanobacteria bloom events, where a ratio of at least 10 , but preferably above 50 , is needed to curtail cyanobacteria dominating blooms.

To realize effective management practices to reduce nutrient for cyanobacteria prevention, many efforts are applied, such as improving the sewage system in the surrounding area [51] and reducing nutrient leakage from agriculture [52]. There are many options to obtaining control over the P levels, such as increasing the efficiency of the phosphorus uptake by crops in the farmland, recycling and reusing phosphorus in water bodies, and promoting efficient wastewater treatment, especially at individual wastewater treatment plants around Lake Vombsjön, which requires the involvement and investment of many cooperating stakeholders. In order to optimize the management of Lake Vombsjön and other lakes providing drinking water, we recommend monitoring and reduction of phosphorus and dissolved nitrogen in concert.

Supplementary Materials: The following are available online at http:/ /www.mdpi.com/2073-4441/10/7/919/s1, Figure S1: Location of Lake Vombsjön in Scania, Figure S2a: Multi-year dynamics (solid line) and trend (dashed line) in TN (blue) and TP (red) at the inlet of the Björkaån River (The main inlet of Lake Vombsjön), Figure S2b: Seasonal dynamics (solid line) and trend (dashed line) in TP and TN concentrations $(\mu \mathrm{g} / \mathrm{L})$ at the outlet of Lake Vombsjön, Figure S2c: Yearly differences in yearly TN and TP transport (kg/year) between the main inlet and the outlet of Lake Vombsjön during the period of 1999-2015, Figure S3: The average monthly dissolved phosphorus concentration $\left(\mathrm{PO}_{4}-\mathrm{P} \mu \mathrm{g} / \mathrm{L}\right)$ at the outlet of Lake Vombsjön during the period of 1999-2015, Figure S4: Average monthly values for the amount of TN and TP found in the main inlet and the main outlet of Lake Vombsjön during the period of 1999 to 2015.

Author Contributions: Conceptualization, J.L. and K.M.P.; Methodology, J.L.; Software, J.L.; Validation, J.L., K.M.P. and L.A.H.; Formal Analysis, J.L.; Investigation, J.L.; Resources, J.L.; Data Curation, J.L.; Writing-Original Draft Preparation, J.L.; Writing-Review \& Editing, J.L., K.M.P. and L.A.H.; Visualization, J.L.; Supervision, K.M.P. and L.A.H.; Project Administration, K.M.P.; Funding Acquisition, K.M.P. 
Funding: This research was funded by Formas-The Swedish Research Council for Environment, Agricultural Sciences and Spatial Planning grant number 2017-00303. This project is also financially supported by Sydvatten and Sweden Water Research.

Acknowledgments: This work was mainly executed during Young Scientist Summer Program 2017 at IIASA, i.e., International Institute for Applied System Analysis. Many thanks to Professor Peter Burek for his kind supervision and the whole WATER group at IIASA for their support.

Conflicts of Interest: The authors declare no conflict of interest.

\section{References}

1. Chorus, I.; Bartram, J. Toxic Cyanobacteria in Water: A Guide to Their Public Health Consequences, Monitoring and Management; World Health Organization: Geneva, Switzerland, 1999; ISBN 0419239308.

2. Paerl, H.W.; Huisman, J. Blooms like it hot. Science 2008, 320, 57-58. [CrossRef] [PubMed]

3. Yang, X.; Wu, X.; Hao, H.; He, Z. Mechanisms and assessment of water eutrophication. J. Zhejiang Univ. Sci. B 2008, 9, 197-209. [CrossRef] [PubMed]

4. Ekholm, P. N:P Ratios in Estimating Nutrient Limitation in Aquatic Systems; Finnish Environment Institute: Helsingfors, Finland, 2008; pp. 11-14.

5. Jeppesen, E.; Kronvang, B.; Meerhoff, M.; Søndergaard, M.; Hansen, K.M.; Andersen, H.E.; Lauridsen, T.L.; Liboriussen, L.; Beklioglu, M.; Özen, A.; et al. Climate Change Effects on Runoff, Catchment Phosphorus Loading and Lake Ecological State, and Potential Adaptations. J. Environ. Qual. 2009, 38, 1930. [CrossRef] [PubMed]

6. Urrutia-Cordero, P.; Ekvall, M.K.; Hansson, L.A. Local food web management increases resilience and buffers against global change effects on freshwaters. Sci. Rep. 2016, 6, 1-9. [CrossRef] [PubMed]

7. Ger, K.A.; Urrutia-Cordero, P.; Frost, P.C.; Hansson, L.A.; Sarnelle, O.; Wilson, A.E.; Lürling, M. The interaction between cyanobacteria and zooplankton in a more eutrophic world. Harmful Algae 2016, 54, 128-144. [CrossRef] [PubMed]

8. Hansson, L.A.; Gustafsson, S.; Rengefors, K.; Bomark, L. Cyanobacterial chemical warfare affects zooplankton community composition. Freshw. Biol. 2007, 52, 1290-1301. [CrossRef]

9. US EPA Small Systems with a Big Problem: Harmful Algal Blooms. Available online: https://www.epa. gov/sciencematters/small-systems-big-problem-harmful-algal-blooms (accessed on 23 April 2018).

10. Westrick, J.A.; Szlag, D.C.; Southwell, B.J.; Sinclair, J. A review of cyanobacteria and cyanotoxins removal/inactivation in drinking water treatment. Anal. Bioanal. Chem. 2010, 397, 1705-1714. [CrossRef] [PubMed]

11. Pestana, C.J.; Reeve, P.J.; Sawade, E.; Voldoire, C.F.; Newton, K.; Praptiwi, R.; Collingnon, L.; Dreyfus, J.; Hobson, P.; Gaget, V.; et al. Fate of cyanobacteria in drinking water treatment plant lagoon supernatant and sludge. Sci. Total Environ. 2016, 565, 1192-1200. [CrossRef] [PubMed]

12. Konopka, A.; Brock, T.D. Effect of temperature on blue-green algae (Cyanobacteria) in Lake Mendota. Appl. Environ. Microbiol. 1978, 36, 572-576. [PubMed]

13. Whitton, B.A. (Ed.) Ecology of Cyanobacteria II: Their Diversity in Space and Time; Springer: Dordrecht, The Netherlands, 2012; ISBN 978-94-007-3855-3.

14. Bakker, E.S.; Hilt, S. Impact of water-level fluctuations on cyanobacterial blooms: Options for management. Aquat. Ecol. 2016, 50, 485-498. [CrossRef]

15. Jiang, H.B.; Lou, W.J.; Ke, W.T.; Song, W.Y.; Price, N.M.; Qiu, B.S. New insights into iron acquisition by cyanobacteria: An essential role for ExbB-ExbD complex in inorganic iron uptake. ISME J. 2015, 9, 297-309. [CrossRef] [PubMed]

16. Xu, H.; Paerl, H.W.; Qin, B.; Zhu, G.; Hall, N.S.; Wu, Y. Determining critical nutrient thresholds needed to control harmful cyanobacterial blooms in eutrophic Lake Taihu, China. Environ. Sci. Technol. 2015, 49, 1051-1059. [CrossRef] [PubMed]

17. Yuan, L.L.; Pollard, A.I. Deriving nutrient targets to prevent excessive cyanobacterial densities in U.S. lakes and reservoirs. Freshw. Biol. 2015, 60, 1901-1916. [CrossRef]

18. Harmful, C.; Blooms, A. Cyanobacterial Harmful Algal Blooms: State of the Science and Research Needs; Springer: New York, NY, USA, 2008; Volume 619, ISBN 9780387758640. 
19. O'Neil, J.M.; Davis, T.W.; Burford, M.A.; Gobler, C.J. The rise of harmful cyanobacteria blooms: The potential roles of eutrophication and climate change. Harmful Algae 2012, 14, 313-334. [CrossRef]

20. Government of Canada. ARCHIVED-Environment and Climate Change Canada-Water-Phosphorus and Excess Algal Growth. Available online: http:/ / www.ec.gc.ca/grandslacs-greatlakes/default.asp?lang=en\& $\mathrm{n}=6201 \mathrm{fd} 24-1$ (accessed on 20 April 2018).

21. Huang, L.; Fang, H.; He, G.; Jiang, H.; Wang, C. Effects of internal loading on phosphorus distribution in the Taihu Lake driven by wind waves and lake currents. Environ. Pollut. 2016, 219, 760-773. [CrossRef] [PubMed]

22. Li, J.; Parkefelt, L.; Persson, K.M.; Pekar, H. Improving cyanobacteria and cyanotoxin monitoring in surface waters for drinking water supply. J. Water Secur. 2017, 3. [CrossRef]

23. Herrero, A.; Muro-Pastor, A.M.; Flores, E. Nitrogen control in cyanobacteria. J. Bacteriol. 2001, 183, 411-425. [CrossRef] [PubMed]

24. Issa, A.A.-S.; Abd-Alla, M.H.; Ohyama, T. Nitrogen Fixing Cyanobacteria: Future Prospect. In Advances in Biology and Ecology of Nitrogen Fixation; InTechOpen: London, England, 2014; pp. 23-48. ISBN 978-953-51-1216-7.

25. Beversdorf, L.J.; Miller, T.R.; McMahon, K.D. The Role of Nitrogen Fixation in Cyanobacterial Bloom Toxicity in a Temperate, Eutrophic Lake. PLoS ONE 2013, 8. [CrossRef] [PubMed]

26. Horst, G.P.; Sarnelle, O.; White, J.D.; Hamilton, S.K.; Kaul, R.R.B.; Bressie, J.D. Nitrogen availability increases the toxin quota of a harmful cyanobacterium, Microcystis aeruginosa. Water Res. 2014, 54, 188-198. [CrossRef] [PubMed]

27. Schindler, D.W. Evolution of Phosphorus Limitation in Lakes. Science 1977, 195, 260-262. [CrossRef] [PubMed]

28. Havens, K.E.; James, R.T.; East, T.L.; Smith, V.H. N:P ratios, light limitation, and cyanobacterial dominance in a subtropical lake impacted by non-point source nutrient pollution. Environ. Pollut. 2003, 122, 379-390. [CrossRef]

29. Smith, V.H. Low Nitrogen to Phosphorus Ratios Favor Dominance by Blue-Green Algae in Lake Phytoplankton. Science 1983, 221, 669-671. [CrossRef] [PubMed]

30. Hudnell, H.K.; Dortch, Q.; Zenick, H. Cyanobacterial Harmful Algal Blooms: Chapter 1: An Overview of the Interagency, International Symposium on Cyanobacterial Harmful Algal Blooms (ISOC-HAB): Advancing the Scientific Understanding of Freshwater Harmful Algal Blooms. In U.S. Environmental Protection Agency Papers; U.S. Environmental Protection Agency: Washington, DC, USA, 2008; Volume 39.

31. Duarte, C.M.; Conley, D.J.; Carstensen, J.; Sánchez-Camacho, M. Return to Neverland: Shifting Baselines Affect Eutrophication Restoration Targets. Estuar. Coasts 2009, 32, 29-36. [CrossRef]

32. Gsell, A.S.; Scharfenberger, U.; Özkundakci, D.; Walters, A.; Hansson, L.-A.; Janssen, A.B.G.; Nõges, P.; Reid, P.C.; Schindler, D.E.; Van Donk, E.; et al. Evaluating early-warning indicators of critical transitions in natural aquatic ecosystems. Proc. Natl. Acad. Sci. USA 2016, 113, E8089-E8095. [CrossRef] [PubMed]

33. Rigosi, A.; Carey, C.C.; Ibelings, B.W.; Brookes, J.D. The interaction between climate warming and eutrophication to promote cyanobacteria is dependent on trophic state and varies among taxa. Limnol. Oceanogr. 2014, 59, 99-114. [CrossRef]

34. SMHI. Svenskt Vattenarkiv. Available online: https://www.smhi.se/klimatdata/hydrologi/svensktvattenarkiv (accessed on 20 April 2018).

35. SMHI Vattenwebb-Älvar, Floder, Åar, Bäckar, Sjöar, S-HYPE, Vattenmyndigheten. Available online: http: / /vattenweb.smhi.se/ (accessed on 20 April 2018).

36. Vattenanknuten Recipientkontroll. Regeringsuppdrag-Havs-Och Vattenmyndigheten. 2014. Available online: https:/ / www.havochvatten.se/hav/uppdrag--kontakt/vart-uppdrag/regeringsuppdrag/ regeringsuppdrag/vattenanknuten-recipientkontroll-2014.html (accessed on 20 April 2018).

37. Provtagnings-Och Analysprogram. Kävlingeåns Vattenvårdsförbund. Available online: http://kavlingeansvvf.com/undersokningar/provtagnings-och-analysprogram/ (accessed on 23 April 2018).

38. Olsson, A.; Svärd, C.; Madeleine, S. Kävlingeån 2016 Kävlingeåns Vattenråd; Kävlingeåns vattenråd: Lund, Sweden, 2017; Available online: http://www.kavlingeans-vvf.com/wp-content/uploads/2017/ 05/Kavlingean_arsrapport_2016.pdf (accessed on 21 May 2018).

39. Lund, J.W.G.; Kipling, C.; Le Cren, E.D. The inverted microscope method of estimating algal numbers and the statistical basis of estimations by counting. Hydrobiologia 1958, 11, 143-170. [CrossRef] 
40. Jacquemot, P.; Li, J.; Parkefelt, L.; Persson, T.; Feuillade, G.; Sydvatten, Lund, Sweden. 2016; Unpublished Work.

41. Lehman, A.; O’Rourke, N.; Hatcher, L.; Stepanski, E.J. JMP ${ }^{\circledR}$ for Basic Univariate and Multivariate Statistics Methods for Researchers and Social Scientists Second Edition; SAS Institute Inc.: Cary, NC, USA, 2013.

42. Poutot, F. Investigation of the Phosphorus Balance in the Vomb Lake; Sydvatten: Lund, Sweden, 2014.

43. Sundahl, A.-C.; Wennberg, C.; Tilly, L.; Wettemark, F.; Magnusson, P.; Schuster, J. Vombsjön-ett Ramdirektioprojekt Vombsjön-A Water Framework Directive Project; Föreningen Vatten: Stockholm, Sweden, 2008; pp. 129-136.

44. Lindegarth, M.; Carstensen, J.; Drakare, S.; Johnson, R.K.; Nyström Sandman, A.; Söderpalm, A.W.S.A. Ecological Assessment of Swedish Water Bodies; Swedish Institute for the Marine Environment: Göteborg, Sweden, 2016.

45. Chorus, I. Current Approaches to Cyanotoxin Risk Assessment, Risk Management and Regulations in Different Countries. 2012. Available online: http:/ / www.uba.de/uba-info-medien-e/4390.html (accessed on 23 May 2018).

46. WHO. Cyanobacterial Toxins: Microcystin-LR in Drinking-Water Background Document for Development of WHO Guidelines for Drinking-Water Quality; WHO: Geneva, Switzerland, 2003.

47. Steffen, M.M.; Belisle, B.S.; Watson, S.B.; Boyer, G.L.; Wilhelm, S.W. Status, causes and controls of cyanobacterial blooms in Lake Erie. J. Great Lakes Res. 2014, 40, 215-225. [CrossRef]

48. Morris, D.P.; Lewis, W.M. Phytoplankton nutrient limitation in Colorado mountain lakes. Freshw. Biol. 1988, 20, 315-327. [CrossRef]

49. Dolman, A.M.; Wiedner, C. Predicting phytoplankton biomass and estimating critical N:P ratios with piecewise models that conform to Liebig's law of the minimum. Freshw. Biol. 2015, 60, 686-697. [CrossRef]

50. Kolzau, S.; Wiedner, C.; Rücker, J.; Köhler, J.; Köhler, A.; Dolman, A.M. Seasonal patterns of Nitrogen and Phosphorus limitation in four German Lakes and the predictability of limitation status from ambient nutrient concentrations. PLoS ONE 2014, 9. [CrossRef] [PubMed]

51. GNF-Success Lake Constance II. Available online: http://www.globalnature.org/19081/Success-LakeConstance-I/Success-Lake-Constance-II/02_vorlage.asp (accessed on 23 May 2018).

52. Lake Erie Action Plan to Reduce Phosphorus Loads by $40 \%$. Available online: https: / /www.watercanada. net/lake-erie-action-plan-to-reduce-phosphorus-loads-by-40/ (accessed on 23 May 2018).

(C) 2018 by the authors. Licensee MDPI, Basel, Switzerland. This article is an open access article distributed under the terms and conditions of the Creative Commons Attribution (CC BY) license (http:/ / creativecommons.org/licenses/by/4.0/). 